\title{
1788 YILINDA J. M. KORABINSKY TARAFINDAN YAZILMIŞ TÜRKÇE GRAMER
} KİTABI

\author{
Beytullah BEKAR ${ }^{1}$
}

\begin{abstract}
Özet
Arap harfleri dışında başka harflerle yazılmış Türkçe malzemeye transkripsiyon anıtları denir. Yabancılar tarafından yazılmış bilinen en eski transkripsiyon anıtı Codex Cumanicus'tur. 18. yüzyılda yabancılar tarafından hazırlanmıs gramer kitaplarından biri de Johann Matthias Korabinsky'nin "Versuch eines kleinen Türkischen Wörterbuchs mit beygesetzten deutsch, ungurisch und böhmischen Bedeutungen und einer kurzgefaßten türkischen Sprachlehre" adlı eseridir. Makalemizde Korabinsky'nin "Versuch eines kleinen Türkischen Wörterbuchs mit beygesetzten deutsch, ungurisch und böhmischen Bedeutungen und einer kurzgefaßten türkischen Sprachlehre" adlı eserinin ikinci kısmında bulunan gramer bölümü tanıtılmıştır.
\end{abstract}

Anahtar kelimeler: Johann Matthias Korabinsky, Almanca, gramer.

\section{TURKISH GRAMMAR WHICH WAS WRITTEN BY KORABINSKY IN 1788}

\begin{abstract}
Turkish material written without the Arabic alphabet is called transcription monument. The oldest transcription monument which is written by foreigners is Codex Cumanicus. Another grammar book written by foreigners in $18^{\text {th }}$ century is named "Versuch eines kleinen Türkischen Wörterbuchs mit beygesetzten deutsch, ungurisch und böhmischen Bedeutungen und einer kurzgefaßten türkischen Sprachlehre" written by Johann Matthias Korabinsky. In this study the grammar part which is in the second chapter of Korabinsky's "Versuch eines kleinen Türkischen Wörterbuchs mit beygesetzten deutsch, ungurisch und böhmischen Bedeutungen und einer kurzgefaßten türkischen Sprachlehre" was introduced.
\end{abstract}

Keywords: Johann Matthias Korabinsky, German, grammar.

\section{o. Giriş}

"Versuch eines kleinen Türkischen Wörterbuchs mit beigesetzten deutsch ungrisch und böhmischen Bedeutungen, und einer kurzgefatsten türkischen Sprachlehre” adlı eser Çek Cumhuriyeti'nin Moravya eyaletinin başkenti Brünn'deki şehir kütüphanesinde 47658 numarada kayıtlıdır. Eserin yazarı Johann Matthias Korabinskydir (1740-1811). Eserin yazımında Times New Roman ve Fraktur karakterleri kullanılmıştır. Eser iki bölüm olup 244 sayfadan oluşmaktadır. Birinci bölümde (162 sayfa) Türkçe, Almanca, Macarca ve Çekçe çok dilli bir sözlük, ikinci bölümde ise (78 sayfa) Türkçenin Almanca açıklamalı kısa bir grameri yer almaktadır. Ayrıca eserin baş tarafında yazarın okuyucuya yazmış olduğu kısa bir bölüm mevcuttur.

Çalışmamızın sınırları eserin gramer bölümünden ibaret olduğu için birinci bölümde bulunan sözlük kısmı hakkında bilgi verilmeyecektir.

\section{Eserin Tanıtılmasında İzlenen Yöntem}

Eserin gramer bölümü daha önce de belirtildiği gibi 10 bölümden oluşmuştur. Yazar 1 . bölümde isimler ve çekimlerini, 2. bölümde sıfatlarla ilgili bazı özellikler, 3. bölümde kelime

Yrd. Doç. Dr., Kırklareli Üniversitesi, Fen-Edebiyat Fakültesi, Türk Dili ve Edebiyatı Bölümü, beytullahbekar@klu.edu.tr 
1788 Yılında J. M. Korabinsky Tarafından Yazılmış Türkçe Gramer Kitabı / B. Bekar (20-34. s.)

türetme, 4. bölümde saylar, 5 . bölümde zamirler, 6 . bölümde iyelik ekleri, 7. bölümde fiiller ve zaman çekimleri, 8 . bölümde Türkçenin karakteristik bazı özellikleri, 9. bölümde sıfat fiiller ve 10. bölümde zarflar, edatlar, bağlaçlar ve ünlemler işlenmiştir. Yazar her bölümde açılamalarda bulunmuș ve bu açıklamalara uygun örnekler vermiștir. Özellikle 1., 6., 7. ve 10. bölümlerde açıklamaların ardından çokça örnekler bulunmaktadır. Örneklerin çok olduğu yerlerde birkaç örnek vermekle yetinilmiştir.

Bölümlerin altında bulunan Almanca açılamalar anlama bağlı kalmak üzere serbest bir şekilde Türkçeye aktarılmıştır. Örneklerin yanlarında italik verilen Almanca kısımlar eserin orijinalinde de bulunmaktadır.

\section{Eserin Tanıtımı}

\section{KLEINE TÜRKISCHE SPRACHLEHRE ${ }^{2}, 3$}

\section{Ön Hatırlatma}

1. Türklerin dili Perslerin ve Tatarların diliyle yakın akrabalık göstermektedir. Buna karşın Türk dili Arapçadan çok farklıdır.

2. Arapça ile olan farklılığa rağmen ibadetlerinde Türkler Arapça kullanırlar. Kur'an'ları bu dilde yazılmıştır. Kullandıkları alfabe de, 31 harften oluşan, Arapların kullandıkları alfabedir.

3. Burada amacımız bu dili anlayıp konuşabilen fakat okuyup yazamayan meraklılarına Türkçeyi tanıtmaktır ki çevrelerinde bulunan Türklerle ilişkilerini çıkara dönüştürebilsinler. $\mathrm{Bu}$ sebeple Arap alfabelerine yer verilmemiştir. Eserin basımında yazıldığı gibi okunan Latin alfabeleri kullanılmıştır.

\section{1. İsimler ve İsim Çekimleri (s. 2-9)}

Türkçede Macarcada olduğu gibi isimlerde cinsiyet yoktur: Bu Er dieser Mann, Bu Affareth dieses Weib, Bu Haiban dieses Thier. İsimlerin hem tekil hem de çoğul şekilleri bulunmakta olup isimler 6 hâlde çekime girmektedirler.

$$
\text { Einfach / Singular4 Vielfach/Mehrfach/Plural5 }
$$

$\begin{array}{lll}\text { Nom. }^{6} & \text {-lar }- \text { ler } & \\ \text { Genitiv7 }^{7} & \text {-ung } & \text {-ung } \\ \text { Dativ }^{8} & -\mathrm{e} & -\mathrm{e} \\ \text { Accusativ }^{9} & -\mathrm{i} & -\mathrm{i}\end{array}$

\footnotetext{
2 Türkçenin Küçük Dilbilgisi.

3 Eser kaleme alındığı dönemin yazım kurallarına göre kaleme alınmış olup günümüzde Almanya'da kullanılan Modern Almancadan farklılıklar gösterdiği hususlar bulunmaktadır: dreizehn yerine dreyzehn; zwei yerine zwey; silbe yerine sylbe gibi. Bu tür yazımların orijinaline sadık kalınmıştır.

tekil

çoğul

Nominativ’in kısaltılmışı olup Türkçede yalın hâl demektir. Bundan sonraki çekimlerde yalnızca N. ile gösterilmistir.

Türkçede ilgi hâli demektir. Bundan sonraki çekimlerde yalnızca G. ile gösterilmiştir.

Yönelme hâli. Bundan sonraki çekimlerde yalnızca D. ile gösterilmiştir.

Belirtme hâli. Bundan sonraki çekimlerde yalnızca A. ile gösterilmiştir. 
Turkish Grammar Which Was Written by Korabinsky in 1788 / B. Bekar (p. 20-34)

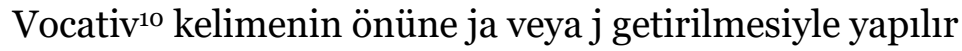

Ablativ $^{11} \quad$-den $\quad$-den

\section{Hatirlatmalar}

1. Ayrılma hâlinde gelen “-den” eki Almancada "von” anlamına gelmektedir.

2. Kelimelerin çoğulları, birinci haldeki kelimenin (yalın hâlin) sonuna -lar veya -ler ekinin getirilmesiyle yapılır. Çoğul kelimelerin diğer hâl çekimleri kelimenin tekil hâlinde olduğu gibidir.

3. -ler ve -lar ekleriyle aynı zamanda fillerde çokluk da yapılmaktadır: jazar er schreibt, jazarlar sie schreiben; eder er macht, ederler sie machen.

Örnek Çekim Tablosu

\section{Einfach/Singular}

N. Beg der Herr

G. Begung des Herrn

D. Bege dem Herrn

A. Begi den Herrn

V. ja Beg o Herr

Abl. Begden von dem Herrn

\section{Mehrfach/Plural}

Begler die Herren

Beglerung der Herren

Beglere den Herren

Begleri die Herren

ja Begler o ihr Herren

Beglerden $v$. den Herren

\section{Hatırlatma}

Ünlüyle biten kelimelerin II. durumu (ilgi hâli) -ung yerine -nung ve III. durum (yönelme hâli) -e yerine -je ekleri getirilerek yapılır.

Örnek Çekim Tablosu

Einfach/Singular

N. Ulu der Todte

G. Ulunung des Todten

D. Uluje dem Todten

A. Uluji den Todten

\section{Mehrfach/Plural}

Ululer die Todten

Ululerung der Todten

Ululere den Todten

Ululeri die Todten

10 Korabinsky tarafından kaleme alınan bu eserde isim çekiminin vokativ hâline de yer verilmiștir. Fakat günümüzde kaleme alınmış Almanca gramer kitaplarında (Röhe K., Balcik I., Wrobel V., Die große Grammatik Deutsch, PONS GmbH, Stuttgart, 2009; Zengin D., Her Yönüyle Modern Almanca, Kurmay Yayınları 5. Baskı, Ankara, 2010; Baldegger M., Müller M., Schneider G., Kontaktschwelle Deutsch als Fremdsprache, Berlin, 1980) vokativ bulunmamaktadır. Türk dillerinden bazllarında vokativ hâlinin bulunduğunu A. A. Yoldaşev (Çev. Bahar Güneş), Türk Dillerinde Sesleniş Sözcükleri (TAED, Sayı 48, s.441446) adlı makalesinde örneklerle vermeye çalışmıştır. Bundan sonraki çekimlerde V. ile gösterilmiştir.

11 Ayrılma hâli. Bundan sonraki çekimlerde yalnızca Abl. şeklinde kısaltılarak gösterilmiştir. 
1788 Yılında J. M. Korabinsky Tarafından Yazılmış Türkçe Gramer Kitabı / B. Bekar (20-34. s.)

V. ja Ulu o du Toder

Abl. Uluden vom Toden ja Ululer o ihr Todten

Ululerden von Todten

\section{Hatirlatma}

Ünsüzle biten bir kelimenin ilk, orta veya son hecesinin içinde a ve o ünlülerinden biri varsa isimlerin tekil ve çoğul türlerinin ayrılma hâli -den yerine -dan getirilerek ve birinci durumda (yalın hâl) -ler yerine -lar getirilerek yapılır.

Örnek Çekim Tablosu
N. Jaradan der Schöpfer
Jaradanlar n. ${ }^{12}$ Jaradanler die Schöpfer
G. Jaradanung des Schöpfers
Jaradanlarung auch ${ }^{13}$ Jaradanlerun der Schöpfer
D. Jaradane dem Schöpfer
Jaradanlare a. ${ }^{14}$ Jaradenlere den Schöpfern
A. Jaradani den Schöpfer
Jaradanlari a. Jaradanleri die Schöpfer
V. ja Jaradan o du Schöpfer
ja Jaradanlar u. Jaradanler o ihr Schöpfer

Abl. Jaradandan u. ${ }^{15}$ Jaradanden vom SchöpferJaradanlardan u. Jaradanlarden von den Schöpfern

\section{Hatırlatma}

'a' ve 'o' ünlüleriyle biten kelimelerin yönelme hâli $-\mathrm{a}^{16}$; tekil ve çoğul türlerinin ayrılma hâli -dan ekiyle yapılır. Aynı zamanda bu kelimelerin çoğul türlerinin yalın hâlleri -ler yerine -lar alır.

\section{Örnek Çekim Tablosu}
N. Baba der Vater
Babalar die Väter
G. Babanung des Vaters Babalarung der Väter
D. Babaja dem Vater Babalare den Vätern
A. Babaj den Vater Babalari die Väter
V. ja Baba o Vater ja Babalar o Väter

Abl. Babadan vom Vater Babalardan von Vätern

\section{Sıfatlarda Derecelendirme ve Karşılaştırma (s. 9-10)}

Her sıfat anlam bakımından bir derece bildirir. Anlam bakımından bu dereceler artırılabilir. Birinci derece positiv, ikinci derece komparativ ve üçüncü derece superlativ'dir.

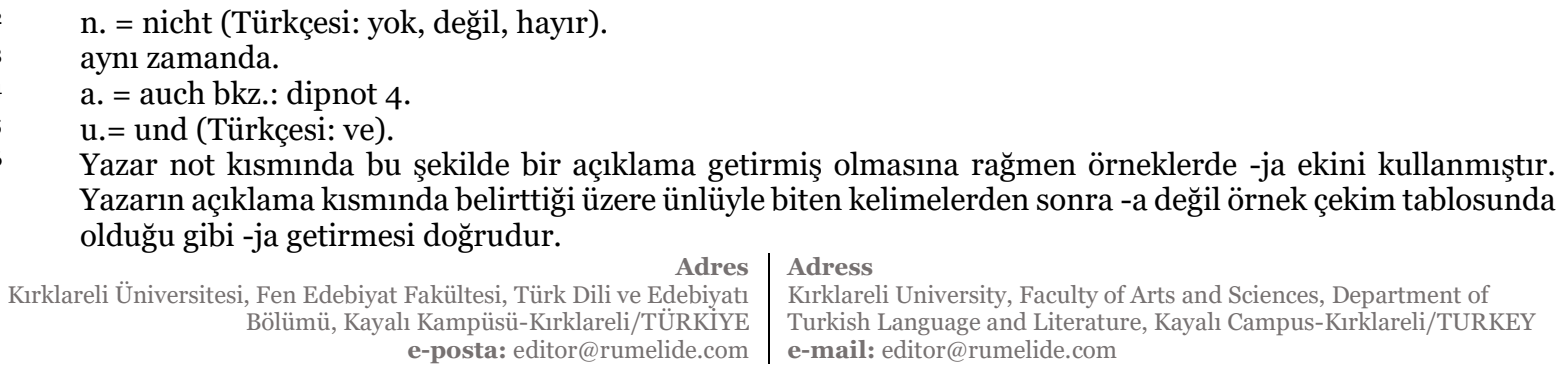


Turkish Grammar Which Was Written by Korabinsky in 1788 / B. Bekar (p. 20-34)

Derecelendirme şu şekilde yapılır: Positiv veya birinci derecedeki sıfatın sonuna -reck getirilerek komparativ; kelimenin başına Gayet sözcüğü getirilerek süperlativ elde edilir.

Örnek

1. Stuffe ${ }^{17}$ Khem bös

2. Stuffe Khemreck böser

3. Stuffe Gajeth Khem der böseste

Karşılaştırma yapmak için diğer bir alternatif ise -den, -dan ekinin karşılaştırılacak olan sözcüğe getirilmesidir; Senden Kutschuk er ist kleiner als du.

\section{Yapım Ekleri ve İşlevleri (s. 10-13)}

I. Ĕ̆er kelime köküne -li eki getirilirse:

Gebe die Waffe Gebeli ein Gewaffneter

Ath das Pferd $\quad$ Athli der Ritter

Agtha das Geld $\quad$ Agthali reich, der Gelt hat

II. Benzer şekilde bir şehirden, ülkeden ve milletten olduğunu göstermek için kelimeler türetilir:

Ottomanli ein Ottomanner

Edringli ein Adrianopler

III. Bir sıfattan isim yapılmak istendiğinde -lük eki getirilir:

Hasta krank Hastalük die Krankheit

Fakür arm $\quad$ Fakürlük die Armuth

IV. Bir fiil isim yapılmak istendiğinde fiilin son hecesi atılır ve yerine -isch eki getirilir:

Soilemak reden Soileisch die Rede

Jurmek gehen Jurisch das Gehen

V. Meslek bildiren kelime türetmek için köke -gi eki getirilir:

Araba der Wagen Arabagi der Fuhrmann

Khilitsch der Säbel Kilisschgi der Säbelmacher, Schwerdtseger

Yabancı dillerden giren bazı meslek isimleri bu kuralın dışındadır: Barbiere'den Berber, Thersi der Schneider, Gerra der Chirurigus vom Griechischen

VI. Küçültme bildiren kelime türetmek için -schük eki getirilir

\footnotetext{
17 derece, kademe. 
1788 Yılında J. M. Korabinsky Tarafından Yazılmış Türkçe Gramer Kitabı / B. Bekar (20-34. s.)

Eff das Haus

Effschük das Häuslein

Oglan der Knabe

Oglanschük das Knäblein

VII. Soyut bazı isimlere Khiar getirilerek bir iş yapma, meslekte çalışma vb. anlamlarda isimler türetilebilir:

Hismeth die Dienstbarkeit

Hismeth Khiar der Diener

Hodabendi die Herrschaft

Hodabendi Khiar der Herr

\section{Saylar (s. 13-15)}

Temel sayılar Türkler tarafından şu şekilde telaffuz edilir:

Bir eins Utsch drey Besch fünfeJedi siebene Dokhüs neune

İcki zwey Dort vier Alti sechse Sekhüs achte On zehne

Bu sayılardan şunlar oluşur:

Onbir eilfe Igermi zwanzig

Onicki zwölfe Igermi bir ein und zwanzig

On utsch dreyzehn $\quad$ Elli fünfzig

On dort vierzehn Jus hundert

Sura bildiren kelimeler:

Biringi/Evuelki der erste Oningi der zehnte

Altingi der sechste Onbiringi der eilfte

Bu şekilde -ingi ekinin yardımıyla sıra bildiren sayılar yapılır:

iusingi der hundertste

Biningi der tausendste

Çoğalma sayıları einfach, zweyfach usw. ${ }^{18}$ khat ekiyle yapılır:

Birkhat einfach Beschkhat füffach

Ickikhat zweyfach Altikhat doppelt dreyfach

Utschkhat dreyfach Jedikhat siebenfach

Dortkhat vierfach

$\mathrm{Bu}$ şekilde sonsuza kadar devam eder

Juskhat hundertfältig Binkhat zehnmahlhundertfach

\footnotetext{
18 bir kat, iki kat vb. 


\section{Zamirler (s. 15-17)}

Zamirler, aşağıda yazılı olan kategorilerde sınıflandırılır:

Anzeigende ${ }^{19}$ : Ben ich, Sen $d u$, Oll dieser oder jener

Fragende ${ }^{20}$ : Khim welcher, welche, welchen

Zueignende $^{21}$ : Benum mein, Senum dein, Onung sein, Bisum unser, Sisum euer.

Zamirlerin hâl çekimi

$$
\text { Einfach Mehrfach }
$$

N. Ben ich Bis wir

G. Benum mein oder meiner Bisum unserer

D. Banga mir Bise uns
A. Beni mich
Bisi wir

Abl. Benden von mir $\quad$ Bisden von uns

Wessen ist das? sorusu Khimungdur şeklinde söylenir.

\section{6. İyelik Ekleri (s. 17-23)}

Türklerde, Macarlarda ve Yahudilerde olduğu gibi mein, dein, sein ${ }^{22}$ zamirlerinin yerini tutan ve iyelik belirten son çekim ekleri vardır.

$M_{e i n}{ }^{23}$ zamiri ismin sonuna getirilen -um veya -m ekiyle ifade edilir. Kelime ünsüzle bitiyorsa -um eki getirilir: Basch der Kopf, Baschum mein Kopf; Ajak der Fuss, Ajakum mein Fuss. Kelime ünlüyle bitiyorsa yalnız -m eki getirilir: Baba der Vater, Babam mein Vater.

Aynı şekilde dein ${ }^{24}$ zamiri isme -ung eki getirilerek yapılır: Basch der Kopf, Baschung dein Kopf; Ell die Hand, Ellung deine Hand. Kelime ünlüyle bitiyorsa -ng eki getirilir: Baba der Vater, Babang dem Vater, Giulge der Schatten, Giulgeng dein Schatten.

Sein ${ }^{25}$ zamiri ünsüzle biten ismin sonuna -i, ünlüyle biten ismin sonuna -ssi eki getirilerek ifade edilir: Basch der Kopf, Baschi sein Kopf; Baba der Vater, Babassi sein Vater. Bu tür kullanım kelimelerin tekil şekillerinde geçerlidir. Kelimelerin çoğul şekillerinde ise kelime ünsüz ile bittiği için daima -i getirilir: Babalar die Väter, Babalari seine Väter.

Unser $^{26}$ zamiri birinci kişi iyelik ekine -us eki getirilerek yapılır: Baba der Vater, Babam mein Vater, Babamus unser Vater.

\footnotetext{
19 kişi/işaret.

20 soru.

21 iyelik.

22 benim, senin, onun.

23 benim.

24 senin.

25 onun.

26 bizim. 
1788 Yılında J. M. Korabinsky Tarafından Yazılmış Türkçe Gramer Kitabı / B. Bekar (20-34. s.)

Euer ${ }^{27}$ zamiri ikinci kişi zamir ekine -us eki getirilerek yapılır: Ellung deine Hand, Ellungus eure Hand

Türkler, yukarıda belirtilen ekleri kullanarak kısa bir şekilde isimlerin iyelik durumlarını belirtirler. Bununla birlikte iyelik eklerinin yanında zamirlerin de kullanıldığ d durumlara rastlanır: Benum Babam mein Vater, Senum ellung deine Hand. Bu tür kullanımlar daha çok vurgu veya nezaket amaçlıdır.

Birleşik zamirler şunlardır: Ben gendum ich selbst, sen gendum du selbst, Ol gendi er selbst Açıklamalarla İlgili Örnek Çekim Tabloları²8:

Einfach

N. Baschung dein Kopf

G. Baschungung deines Kopfs

D. Baschunge deinem Kopf

A. Baschungi deinen Kopf

Abl. Baschungden von deinem Kopf
Mehrfach

Baschungler deine Köpfe

Baschunglerung deine Köpfe

Baschunglere deinen Köpfen

Baschungleri deine Köpfe

Baschunglerden von deinen Köpfen

\section{Fiiller (s. 23-43)}

Türklerde iki tür fiil vardır. Biri -mak, diğeri de -mek ile biter. Her iki tür fiil çekiminde ünlülerini korurlar: Bakmak, Bakarem, Bakaim. Seumek, Severem, Seveim.

\section{Fillere Gelen Zaman Ekleri}

Tekil 1. şahıs gegenwart ${ }^{29}$ çekimi mastar ekinin (-mak) atılıp yerine -rem veya -urem eki getirilmesiyle yapılır. - urem ekinin getirilmesinin daha uygun olduğu yerler pratik yaparak ögrenilir: Korkmak, Korkarem; Agigmak, Agigurem

Bütün dillerde olduğu gibi eklerin getirilişinde ünlü uyumu dikkate alınmaktadır. Fakat genel kullanımda bunun dışına çıkıldığı durumlar da görülmektedir: Severem yerine Severum.

Ayrıca burada 'idmek' ve 'olmak' kelimelerini hatırlatmak gerekir. Biri yapmak diğeri ise olmak anlamındadır. Bu iki kelime genellikle isimlerle birlikte kullanılarak onları fiil yapar: Hasta olmak gesund werden ${ }^{30}$, Hasta idmek gesund machen oder heilen ${ }^{31}$.

Benzer bir özellik de -mek ekinde bulunmaktadır. Ek tekil 1. şahısta atılır ve yerine -erem veya -urem getirilir. Seumek, Severem; Vpmek, Vperem. İki heceli kelimeler genellikle -uerm yerine -erem ekini alırlar. Ulmek, ulurem. Çok az kelime bunun dışındadır.

Bir kural olmasa da üç heceli kelimeler -urem ekini alırlar: Vugredmek, Ugredurem; Egelmek, Egelurem.

\footnotetext{
27 sizin.

28 Kitapta iyelik ekleri maddesi altında verilen her özellikle ilgili çekim tablosu bulunmasına rağmen biz burada tek örnekle yetineceğiz.

29 Almancada gegenwart veya präsens olarak adlandırılan zaman diliminin Türkçedeki karşılığ zaman ve geniş zamanadır.

3o Yazar burada anlamlandırmayı yanlış yapmıştır. Hasta olmak 'krank werden'.

${ }_{31} \quad$ Yazar burada anlamlandırmayı yanlış yapmıştır. Hasta idmek 'krank machen'. 
Turkish Grammar Which Was Written by Korabinsky in 1788 / B. Bekar (p. 20-34)

Das Perfektum ${ }^{32}$ çekimi kelime sonunda bulunan -mek veya -mak ekinin atılıp yerine -dum ekinin getirilmesiyle yapılır: Seumek, Seudum; Tschikmak, Tschikdum.

Das Futurum ${ }^{33}$ ise -im ekinin zaman eki -rem yerine getirilmesiyle yapılır: Severem, Seveim; Jurerem, Jureim.

-urem ekiyle biten kelimelerde u kelimenin son ünlüsüne uyar: Gellirem, Gelluim yerine gelleim olur.

Futuri indicativi ${ }^{34}$ için genellikle Futuri participiï35 eki de kullanılır. Bunun için fiilimsi ekinin sonuna -em veya -am getirilir: Seugeg einer der lieben wird, Seugegem ich werde lieben.

Futuri yerine Präsens ${ }^{36}$ eki biraz önce olmuş bir durumu belirtmek veya göstermek için kullanılır: Gellurem ich komme, Giururem ich sehe. Imperativ37 ise -mak ekinin atılıp yerine -sen getirilmesiyle yapılır: Baksen, Gellsen.

Gerundia ${ }^{8}$ ise -mak ekinin atılıp yerine -up ekinin getirilmesiyle yapılır: Bakup mit beachten, Gellup mit kommen.

Örnek Çekim Tablosu39:

1. -mak mastar ekiyle bitip -arem ve -urem eki alanların çekimi:

Präsens : Jatturem, Jattursen, Jattur, Jatturus, Jattursis, Jatturler

Imperfektum $40 \quad$ : Jatturidum, Jatturidung, Jatturidi, Jatturiduk, Jatturidungus, Jatturleridi

Perfekt : Jattdum, Jattdung, Jattdi, Jattduk, Jattdungus, Jattdiler.

Plusquamperfekt ${ }^{41}$ : Jattmischidum, Jattmischidung, Jattmischidi, Jattmischiduk, Jattmischidungus, Jattmischileridi

Futur I

: Jattaim, Jattasin, Jatta, Jattavuis, Jattasis, Jattalar

Zweite Art des Futur : Jattagagam, Jattagagsan, Jattagagdur, Jattagagus, Jattagagsis, Jattagaglardur.

Imperativ $\quad$ : Jattsen, Jattsen oll, Jattasis, Jattsuler

Conjunctivus ${ }^{42}$ :

Präsens $\quad$ : Jattam, Jattasin, Jatta, Jattavuis, Jattasis, Jattalar

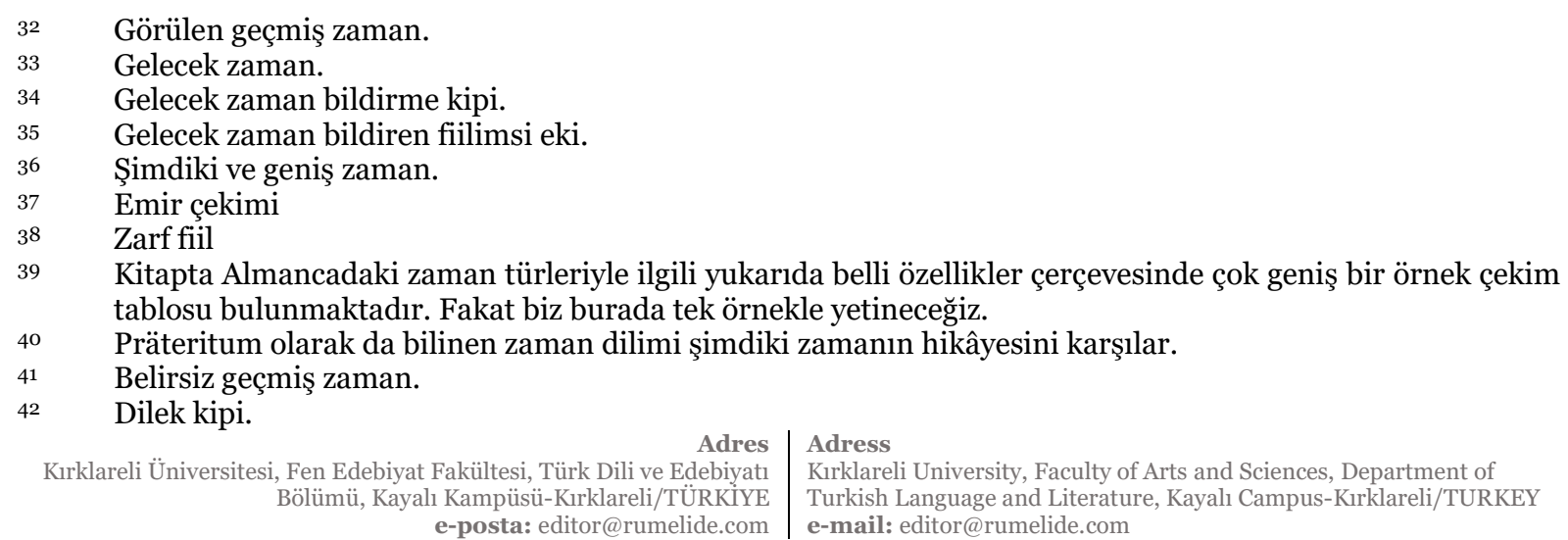


1788 Yılında J. M. Korabinsky Tarafından Yazılmış Türkçe Gramer Kitabı / B. Bekar (20-34. s.)

Präteritum/İmperfekt :Jattagagam, Jattagagsan, Jattagagdur, Jattagagus, Jattagagsis, Jattagaglardur

Imperativ $\quad$ : Jattsen, Jattsen oll, Jattasis, Jattsuler

2. -mek mastar ekiyle bitip -urem ve -erem eki alanların çekimi:

Präsens : Severem, Seversen, Sever, Severus, Seversis, Severler

Präteritum

: Severidum, Severidung, Severidi, Severiduk, Severidungus,

Severleridi

Perfekt

: Seudum, Seudung, Seudi, Seuduk, Seudungus, Seudiler

Gebietende Art 43 :-, Vgredsen, Vgredsen oll, Vgredesis, Vgredsunler

\section{Edilgen Filler}

Edilgen bir fiil ile edilgen olmayan bir fiile zaman eklerinin eklenişinde bir fark yoktur. Yalnız edilgen fiilin farkı -il veya -ilu ekini almasıdır: Vgredurem, Vgredulurem.

Örnek Çekim Tablosu

Präsens

Vgredilurler

Imperfekt : Vgrediluridum, Vgrediluridung, Vgrediluridi, Vgrediluriduk, Vgrediluridingis, Vgrediluridiler

Perfekt

Vgredildilar

: Vgredildum, Vgredildung, Vgredildi, Vgredildik, Vgredildingis,

Plusquamperfekt : Vgredilmischidum, Vgredilmischidung, Vgredilmischidi, Vgredilmischiduk, Vgredilmischidingis, Vgredilmischidiler

Futurum : Vgrediligegim, Vgrediligeksen, Vgrediligekdur, Vgrediligegus, Vgrediligeksus, Vgrediligekler

Imperativ $\quad$ :-, Vgredilsen, Vgredilsen oll, -, Vgredilingsis, Vgredileler onlar

\section{Türkçenin Bazı Karakteristik Özellikleri (s. 43-58)}

Türkler nein ${ }^{44}$ edatının yerine fiile kısaca -me, -ma eki getirerek bu olumsuzluğu yaparlar: Ommak hoffen, Ommamak nicht hoffen.

Mastar ekli șekli iki heceden oluşan fillerde präsens olumsuz çekimini yapmak için ikinci hece atılır ve yerine -masen, -mesen getirilir: Seumek, Seumesen; Baglamak, Baglamasen.

Örnek Çekim Tablosu45:

Präsens: Seumesem, Seumeszin, Seumes, Seumesus, Seumesingis, Seumeszler

\footnotetext{
43 Emir çekimi.

44 hayır, yok, değil.

45 Kitapta Almanca haber ve dilek kipleriyle seumek sözcüğünün olumsuzunun çekimi bulunmasına rağmen biz burada üç zaman çekimini vermekle yetineceğiz. 
Turkish Grammar Which Was Written by Korabinsky in 1788 / B. Bekar (p. 20-34)

İmperfekt: Seumesidum, Seumesidung, Seumesidi, Seumesidik, Seumesidingis, Seumesidiler

Perfekt: Seumedum, Seumedung, Seumedi, Seumedik, Seumedingis, Seumediler.

Aynı şekilde edilgen fiillerin olumsuz şekli de kelimenin ünlülerine göre veya mastar ekinden önceki ünlüye göre -mesem veya -masem getirilerek yapılır: Sevilmek geliebt werden, Sevilmesem ich werde nicht geliebt.

Örnek Çekim Tablosu'46:

Präsens: Sevilmesem, Sevilmesin, Sevilmes, Sevilmesus, Sevilmeszis, Sevilmesler

Imperfekt : Sevilmesidum, Sevilmesidung, Sevilmesidi, Sevilmesidik, Sevilmesidingis, Sevilmesidiler

Perfekt : Sevilmedum, Sevilmedung, Sevilmedi, Sevilmedik, Sevilmedingis, Sevilmediler.

Diğer dillerde, meydana gelen bir duruma etki ettiğini belirtmek için birkaç kelime kullanmak gerekir. Türklerin bu durumu belirtmek için de kendilerine has kullanımları bulunmaktadır. Bunun için -dur veya seyrek de olsa -duru ekini getirirler. Mastar eki -mak veya -mek atılır ve yerine -dururem eki getirilir ve böylece präsens yapılır: Bakmak sehen, Bakdururem ich mache daß mann sehe.

Örnek Çekim Tablosu47:

Präsens

Seufdururler

: Seufdururem, Seufdurursin, Seufdurur, Seufdururis, Seufdurursings,

Perfekt

Seufdurdiler.

: Seufdurdum, Seufdurdung, Seufdurdi, Seufdurdik, Seufdurdingis,

Yine benzer şekilde edilgen fillerde de yapılır: Sevilmek geliebet werden, Sevildururem machen geliebet zu werden.

Ĕger bir durumun meydana gelmemesinde etkisinin olduğunu belirtmek isterlerse yukarıda belirtilen olumsuzluk eki -ma, -me kullanırlar: Bakdururem ich mache da $\beta$ man sehe, Bakdurmesem ich mache daß man nicht sehe.

$\mathrm{Bu}$ dilin ilginç ve kendine has bir özelliği de dönüşlülük durumunun tek bir kelimeyle yapılabilmesidir: Vgmak loben, Vginurem ich lobe mich selbst.

Birlikte veya karşılıklı yapma ifade etmek için çokluk şahıs çekimlerinde - isch getirilir:

Präsens

: Severus, Seversis, Severler, Sevischurus, Sevischursis, Sevischurler

Perfekt

Seuvischudiler.

: Seuduk, Seudungus, Seudiler, Seuvischuduk, Seuvischudungus,

Futur

: Sevevis, Sevesis, Seveler, Sevischuis, Sevischusis, Sevischuler.

\footnotetext{
$46 \quad$ Kitapta Almanca haber ve dilek kipleriyle sevilmek sözcüğünün olumsuzunun çekimi bulunmasına rağmen biz burada üç zaman çekimini vermekle yetineceğiz.

47 Kitapta Almanca haber ve dilek kipleriyle seufdurmek sözcüğünün çekimi bulunmasına rağmen biz burada iki zaman çekimini vermekle yetineceğiz. 
1788 Yılında J. M. Korabinsky Tarafından Yazılmış Türkçe Gramer Kitabı / B. Bekar (20-34. s.)

Mastar şeklindeki kelimelere de getirilebilir: Seumek lieben, Sevischmek einander lieben; Bakmak ansehen, Bakischmak einander ansehen.

\section{Sifat Filler (s. 58 - 6o)}

Mittelwörter oder Participia zaman eklerinden meydana gelmişlerdir. Präsens tekil birinci şahısta -rem yerine -n ekinin getirilmesiyle yapılır: Severem ich liebe, Seven einer der da liebet.

Präsens şahıs çekiminde -urem eki alanlar, sıfat fiil ekini $(-n)$ alacağı zaman ekin başında bulunan u ünlüsü kelimenin ünlüsüne bağlı olarak değişir: Gellurem, Gellun değil Gellen; Vgredurem, Vgredun değil Vgreden olur.

Benzer bir özellik de içinde u ünlüsü bulunan bazı kelimelerde görülür. Bu kelimelere ek gelirken yukarıdaki örnekte olduğu gibi u ünlüsü mastar ekinin ünlüsüne göre değişir: Durmak, Dururem, Durun değil Duran; Bullmak, Bullurem, Bullun değil Bullan olur.

Sıfat fiilin gelecek zaman 1. şahış şekli -rem ekinin atılması ve yerine -geg veya -gag ekinin getirilmesiyle yapılır: Severem, Sevgeg; Bakarem, Bakagag.

Edilgen präteritum yapmak için haber kiplerinden perfekt ve präteritum ekinin sonunda bulunan -dum eki atılır ve yerine -misch getirilir: Sevilmisch ein Geliebter, Ugredilmisch ein Gelehrter.

Futurum Passiv ${ }^{48}$ yapmak için sıfat fiilin gelecek zaman yapımına -il veya -le eklenir: Sevegek einer der lieben wird, Sevilegek einer der geliebt werden soll.

\section{Zarflar (s. $60-78)$}

\section{Yer Gösterenler}

Nerede sorusunun cevabı:49 Itscherde drinnen, Ardinde von hinten, Aschaja unten...

Nereden sorusunun cevabı:50 Buradan von Hinnen, Jugden vom Himmel, Tangriden ve Allachden von Himmelher...

\section{Zaman Belirtenler}

Bugiun heute, Dun gestern, Schindi jetzt, Hersaman immer, Demin schon, Wachtinde zu rechter Zeit...

Günün altı vakti: Temgith, Sabachnamasi, Eynle, Ikendi, Aschkam, Jatozi

Bazı Hususlar:

1. -dek ve -değin eklendiği kelimeye -e kadar anlamı katar: Sabachaddeg veya Sabachadegin bis zur Frühzeit

2. -din geldiği kelimeye önce anlamı katar: Eljumadin jemek jeme bevor du die Hände nicht gewaschen hast eße nicht.

3. -ducte eki çekimlenebilen bir sözcüğe getirildiği zaman yakın zamanda bir işin gerçekleşeceğini bildirir: Acscham jaclaschducte eben als die Nacht einbracht.

\footnotetext{
$48 \quad$ Edilgen gelecek zaman.

Nerede, sorusunun cevabi olanlar.

Nereden, sorusunun cevabi olanlar.
}

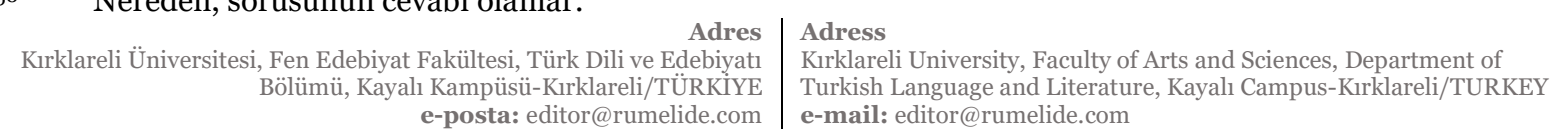


Turkish Grammar Which Was Written by Korabinsky in 1788 / B. Bekar (p. 20-34)

4.-ge eki fiile eklenince kadar anlamı katar: sen gelinge bist du kommst

\section{Sayı Bildirenler}

Birkerre einmahl, Ikikerre zweymal, Dortingi zum vierten vb.

\section{Olumsuzluk Bildirenler}

Jok nein, Jokdur es ist nicht

Degul sözcüğü de kişiler veya eşyalar arası farklılık belirtmek için kullanılan bir olumsuzluk sözcügüüür: Fakur jokdur yerine fakur degul.

-me ve -ma ekleri de daha önce geçtiği gibi olumsuzluk bildiri: Seumek lieben, Seumemek nicht lieben

\section{Onaylama ve Müspetlik Bildirenler}

Schoiledur also ists, Oiledur also ists

\section{Sakınma Belirten Sözler}

Allah saklas Gott bewahre, Allah istemesun, Irakalsun sad sey ferne

\section{İstek Bildirenler}

Kheschke, Nolaidi Wolle Gott, Allach Vuersun Gott gebe es

\section{Soru Bildirenler}

Degulmi ist es nicht also, Nitgun Warum, Ellemi kommt er

\section{Karşılaştırma Bildirenler}

Giojakhi gleichsam, Nitekhim als wie, gleichsam. Gibi sözcüğü sonuna geldiği kelimeye benzerlik, eşitlik anlamı katar: Adam gibi als oder gleichsam ein Mensch

\section{Miktar ve Çokluk Bildirenler}

Tschok viel, Kattitschok meistens, As wenig, Jeter genug. İnge sözcügü de getirildiği kelimeye adet ve çokluk belirtir: Agatschlar japraklaringe so viel als Blätter an dem Bäumen, Dengisler cumlaringe so viel als Sand am Meer vb.

\section{Kararsızlık Bildirenler}

Belki Vielleicht, Kimbillur Wer wei $\beta$

\section{Seslenme Bildirenler}

Jahu o Höre!, Hude Steh

\section{Yanıtlama Bildirenler}

Ne uuar? Was ists, Bundaim, hier bin ich.

\section{Yemin Bildirenler}


1788 Yılında J. M. Korabinsky Tarafından Yazılmış Türkçe Gramer Kitabı / B. Bekar (20-34. s.)

Ballaha bille um Gottes Willen, Etmek Hakitschun durchs Brodt

\section{Edatlar}

$Z u$, -ja, -je veya -a,-e ile ifade edilir. Kelime ünlüyle biterse -ja, -je ünsüzle biterse -a, -e getirilir: Baba der Vater, Babaja zum Vater; Ajak der Fu $\beta$, Ajaka zum Fu $\beta$.

Bey51, -da ve -de ile ifade edilir: Babamda bey dem Vater, Begde bey dem Herrn. Aynı şekilde in sözcüğü de aynı ekle yapılır: Pasarda auf dem Platz, Effde im Hause, Elde in der Hand.

Benzer şekilde vor, außen, herum, zwischen, oben, neben, unten, durch edatları - da veya -de ile ifade edilir: Ung der vordere Theil, Ungin deșsen vorderer Theil, Unginde im vordern Theil deßelben, altinde im untern Theil.

Vor: Illeru ve Vnginde aynı şekilde Khattinde: Bir ayden illeru vor einem Monat

Benzer ssekilde yazar gegen, entgegen, durch, darnach, nach, außer, für, ohne, drinnen, innerhalb, zwischen edatlarını açıklamıştır.

\section{Bağlaçlar}

Weder, Ne: Ne ben giderem ne sen gider sen weder ich werde gehen, noch du wirst gehen.

Es sey denn, -inge: Ay Carin domainge oinamas der Bär tanzt nicht es sey dann er sey satt.

Oder, entweder: Ja ben, ja sen entweder ich oder du.

\section{Ünlemler}

\section{Yakınma Bildirenler}

Vach, Eubach, Hei medet ach, auweh

\section{Gülme Bildirenler}

Ha ha, ha ha

\section{Ă̆lama Bildirenler}

Hej hej.

\section{Beğenme Bildirenler}

Ey afferum, giusel.

\section{Şaşkınlık Bildirenler}

Allach, allach, Allahsaklasun.

\section{Kaynakça}

Korabinsky, J.M. (1788). Versuch eines kleinen Türkischen Wörterbuchs mit beygesetzten deutsch-ungarisch und böhmischen Bedeutungen, und einer kurzgefaßten türkischen Sprachlehre, Preßburg.

\footnotetext{
$51 \quad$ Modern Almancada 'bei' şeklinde yazılmaktadır. 
34/ RumeliDE Journal of Language and Literature Studies 2016.7 (October)

Turkish Grammar Which Was Written by Korabinsky in 1788 / B. Bekar (p. 20-34)

Röhe K., Balcik I., Wrobel V. (2009). Die große Grammatik Deutsch, PONS GmbH, Stuttgart.

Zengin D. (2010). Her Yönüyle Modern Almanca, Kurmay Yayınları 5. Baskı, Ankara.

Baldegger M., Müller M., Schneider G., Kontaktschwelle Deutsch als Fremdsprache, Berlin, 1980.

Steuerwald, K. (1993). Almanca Türkçe Sözlük, Otto Harrassowitz GmbH, Wiesbaden.

https://de.wikipedia.org/wiki/Johann_Matthias_Korabinsky (erişim tarihi: 01.08.2016) 